Check for updates

Cite this: RSC Adv., 2017, 7, 28358

Received 19th April 2017

Accepted 18th May 2017

DOI: 10.1039/c7ra04419d

rsc.li/rsc-advances

\section{UV-crosslinked poly(arylene ether sulfone) - LAPONITE® nanocomposites for proton exchange membranes $\dagger$}

\author{
Sun Hwa Lee, $\ddagger^{\mathrm{a}}$ Won Jun Lee, (D) $\ddagger^{\mathrm{ab}}$ Tae Kyoung Kim, ${ }^{\text {cd }}$ Mustafa K. Bayazit, \\ Sang Ouk Kim (D) and Yeong Suk Choi ${ }^{* e}$
}

The dimensional stability and barrier properties of proton exchange membranes are critical issues for highperformance proton exchange membrane fuel cells (PEMFCs). In this work, we introduce a viable and effective strategy for preparing high proton-conductive polymer membranes with remarkable dimensional stability and barrier properties. Sulfonated poly(arylene sulfone)s (sPASs) with a UV-crosslinkable monomer, 2,2'-diallylbisphenol A (DABPA), is successfully synthesized via condensation polymerization, showing competitive molecular weights and sulfonation degrees to the neat polymer. Crosslinked nanocomposite membranes can be fabricated by incorporating soft bridge molecules and exfoliated LAPONITE® nanofillers, and subsequent UV-crosslinking. The sPAS-LAPONITE® nanocomposite membranes show greatly improved dimensional stabilities and barrier properties including remarkably reduced swelling ratio in solvent or methanol aqueous solutions. These enhanced properties lead to excellent performance in a direct methanol fuel cell (DMFC) test, surpassing that of a commercially available Nafion membrane based devices.

\section{Introduction}

The design of proton exchange membranes (PEMs) and their deterministic performance are core opportunities as well as challenges for direct methanol fuel cells (DMFC). ${ }^{1-4}$ The membrane plays a pivotal role in the DMFC, ${ }^{\mathbf{5}, \mathbf{6}}$ isolating electronically the anode from the cathode, preventing the loss of methanol, and enabling transport of protons. ${ }^{7,8}$ Therefore, the ability to provide enhanced conductivity at a reduced methanol crossover with superior dimensional stabilities has been a major focus in membrane research..$^{9-11}$ However, perfluorinated polymer PEMs, such as Nafion or Aciplex, ${ }^{12,13}$ show appropriate conductivity in the range of $0.1 \mathrm{~S} \mathrm{~cm}^{-1}$ but suffer high methanol crossover and geometry deterioration under moderate operating conditions (up to $\left.90{ }^{\circ} \mathrm{C}\right) .{ }^{14-16}$

So far, composite membranes have emerged with the function to reduce methanol crossover significantly by engineering

${ }^{a}$ Department of Materials Science and Engineering, KAIST, 291 Daehak-ro, Yuseong-gu, Daejeon 34141, Republic of Korea

${ }^{b}$ Department of Chemistry, Imperial College London, London, SW7 2AZ, UK

${ }^{c}$ Research Institute of Chemical and Electronic Materials, Samsung Cheil Industries Inc., Uiwang-si, 437-711, Republic of Korea

${ }^{d}$ A123 Systems, 200 West St., Waltham, MA 02451, USA

${ }^{e}$ Organic Materials Lab, Samsung Advanced Institute of Technology, 130, Samsung-ro, Yeongtong-gu, Suwon-si, Gyeonggi-do, 16678, Republic of Korea. E-mail: yeongsuk. choi@samsung.com

$\dagger$ Electronic supplementary information (ESI) available. See DOI: 10.1039/c7ra04419d

\$ These authors contributed equally to this work. their chemical structures $\left(<6 \times 10^{-6} \mathrm{~cm}^{2} \mathrm{~s}^{-1}\right) \cdot{ }^{17,18}$ In particular, sulfonated poly(arylene sulfone) (sPAS) composite membranes have demonstrated their great potential with improved mechanical strength, ${ }^{19}$ low methanol permeability, ${ }^{20}$ and lower cell resistance in the presence of additives, ${ }^{21}$ such as clay, ${ }^{22,23}$ $\mathrm{CNTs}^{24}$ and graphene. ${ }^{25,26}$ Alternative approaches to adapt the surface properties on sPAS include diazotization reactions, ${ }^{27}$ grafting sulfonic acid side groups, ${ }^{28}$ and copolymerization. ${ }^{29,30}$ Intrinsically, when PAS has a high sulfonation degree which is required for high proton conductivity, ${ }^{31}$ it gives rise to excessive swelling in aqueous media, ${ }^{32}$ thereby leading to considerable degradation in mechanical robustness, ${ }^{33}$ low dimensional stability and high methanol permeability in the long-term. ${ }^{34}$ In this regard, securing both dimensional stability and barrier properties with high proton conductive PAS membrane is a formidable challenge. ${ }^{20,35-39}$

Here, we present a straightforward fabrication of sPASLAPONITE® composite membranes via direct copolymerization and photo-crosslinking, which have distinguished dimensional stability, low methanol permeability and high proton conductivity. UV-crosslinkable sPAS random copolymers were copolymerized with diallyl bisphenol A monomers.

The functional allyl groups on bisphenol A monomer could generate a high crosslinked dense network that results in considerably enhanced chemical and mechanical stability without deteriorating its high proton conductivity. Furthermore, the introduction of completely exfoliated LAPONITE® could improve the selective proton/methanol transport of SPAS without any hindrance of proton pathways (Fig. 1). The effects 


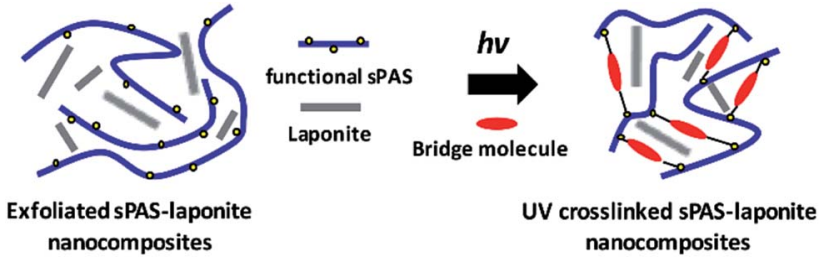

Fig. 1 Conceptual schematic for the fabrication of the UV-crosslinked sPAS-LAPONITE® nanocomposite membranes.

of UV-crosslinking sPAS in the presence of LAPONITE $®$, such as glass transition temperatures, the swelling behavior, the methanol diffusion coefficient, mechanical strength, and the proton conductivity, were thoroughly investigated. Furthermore, the effect of UV-crosslinked SPAS-LAPONITE® nanocomposite membranes on DMFC performances was elucidated.

\section{Experimental}

\subsection{Materials}

4,4'-Dichlorodiphenyl sulfone (DCDPS, Tokyo Chemical Inc.), sulfonated $4,4^{\prime}$ dichlorodiphenyl sulfone, sodium salt ( $\mathrm{Na}-$ sDCDPS), ${ }^{40}$ and bisphenol A (BPA, Aldrich) were purified by recrystallization before condensation polymerization. 2,2'-Diallylbisphenol A (DABPA, Aldrich), ${ }^{41,42}$ 1,6-hexanediol diacrylate (HDDA, Aldrich), benzophenone (Aldrich), and LAPONITE® (Laporte Absorbents) were used as received. Before polymerization, the purity of DABPA was analyzed using an Agilent 5973N gas chromatography-mass spectrometry (GC-MS) for calculating stoichiometric ratio. The GC-MS data showed that the purchased DABPA consisted of $88 \%$ diallyl-BPA, $5 \%$ triallyl BPA, and $2 \%$ untreated BPA. Based on the GC-MS results, we determine that the contents of diol in DABPA is about $95 \%$ and the polymerization recipe was prepared with determined purity of DABPA, $95 \%$.

\subsection{Synthesis of UV-crosslinkable SPAS}

UV-crosslinkable sPASs were synthesized, as described in our previous work. ${ }^{22,23}$ Briefly, the stoichiometric ratio of dihalides (4,4'-dichlorodiphenyl sulfone (DCDPS) and sulfonated 4,4'dichlorodiphenyl sulfone, sodium salt (Na-sDCDPS)) to diols (bisphenol A (BPA) and DABPA) was $1: 1$. Amounts of DABPA and Na-sDCDPS in the diols and dihalides were varied as listed in Table 1. The monomers, potassium carbonate $\left(\mathrm{K}_{2} \mathrm{CO}_{3}\right.$, Aldrich), $N$-methyl-2-pyrrolidinone (NMP), and toluene were added into a two-necked flask, equipped with a dean-stark trap and an $\mathrm{N}_{2}$ inlet. Polymerization was carried out at $180^{\circ} \mathrm{C}$ for $6 \mathrm{~h}$. After the completion of polymerization, the reactor was aircooled to room temperature. The synthesized UVcrosslinkable sPAS was collected by precipitation into 2-propanol and washed with deionized water three times.

\subsection{Dispersion of LAPONITE® on UV-crosslinkable sPAS}

Pre-determined amounts of LAPONITE $®$ was dispersed in 10 $\mathrm{mL}$ of NMP by ultrasonication for $1 \mathrm{~h}$. After the temperature of the reactor for crosslinkable sPAS polymerization was lowered to $70^{\circ} \mathrm{C}$, LAPONITE $®$ dispersed in NMP was transferred into the reactor and stirred for $12 \mathrm{~h}$. The prepared SPAS-LAPONITE ${ }^{\circledR}$ nanocomposites were recovered by precipitation into 2-propanol and dissolved and washed with deionized water three times. It should be noted that LAPONITE® is not dissolved in both 2-propanol and deionized water.

\subsection{Fabrication of UV-crosslinked membrane}

UV-crosslinkable SPAS samples with or without LAPONITE® were stirred and dissolved in NMP for more than 24 h. 1,6Hexanediol diacrylate (HDDA) and benzophenone were added to the solution and stirred until they became transparent. ${ }^{43}$ The molar ratio of the acrylate groups of HDDA to the allyl groups of sPAS was varied from $0 \%$ to $15 \%$. $3 \mathrm{wt} \%$ of benzophenone was used as a photoinitiator for UV-crosslinking. ${ }^{44}$ The UVcrosslinkable sPAS films were prepared via doctor blade technique from functional sPAS solutions. The blade gap and concentration of polymer dope were $500 \mu \mathrm{m}$ and $10 \mathrm{wt} \%$, respectively which results in an average film thickness of $\sim 50$ $\mu \mathrm{m}$. Followingly, obtained films were crosslinked using a $365 \mathrm{~nm}$ mercury lamp (ORIEL) for $25 \mathrm{~min}$. After crosslinking, the films were dried under vacuum at $150{ }^{\circ} \mathrm{C}$ for $24 \mathrm{~h}$ to remove any residual solvent. Before DMFC performance tests, UV-cured membranes were boiled in a $1 \mathrm{M} \mathrm{H}_{2} \mathrm{SO}_{4}$ aqueous solution at $95{ }^{\circ} \mathrm{C}$ for $2 \mathrm{~h}$ to transform the Na salt-form membranes into

Table 1 Molecular weights and chemical composition of synthesized sPASs, sulfonation degrees and DABPA contents were measured from NMR analysis ${ }^{a}$

\begin{tabular}{lllll}
\hline $\begin{array}{l}\text { The molar ratio (\%) } \\
\text { of DCDPS/Na-sDCDPS/BPA/DABPA }\end{array}$ & $M_{\mathrm{n}}$ & $M_{\mathrm{w}}$ & $\begin{array}{l}\text { Sulfonation degree [\%] } \\
\text { (feed ratio/measured) }^{b}\end{array}$ & $\begin{array}{l}\text { DABPA content [\%] } \\
\text { ffeed ratio/measured) }^{c}\end{array}$ \\
\hline $70 / 30 / 100 / 0$ & 809000 & 1273000 & $30 / 28.0$ & $0 / 0$ \\
$70 / 30 / 90 / 10$ & 981000 & 1928000 & $30 / 27.6$ & $10 / 8.5$ \\
$70 / 30 / 75 / 25$ & 923000 & 1766000 & $30 / 29.1$ & $25 / 22.1$ \\
$70 / 30 / 50 / 50$ & 920000 & 1700000 & $30 / 29.4$ & $50 / 43.2$ \\
$70 / 30 / 25 / 75$ & N/A (gel) & N/A (gel) & $30 / 30.5$ & $75 / 69.6$ \\
$70 / 30 / 0 / 100$ & N/A (gel) & N/A (gel) & $30 / 33.3$ & $100 / 81.2$ \\
$80 / 20 / 75 / 25$ & 1202000 & 2394000 & $20 / 20.0$ & $25 / 20.0$
\end{tabular}

${ }^{a} M_{\mathrm{n}}$ : number-average molecular weight, $M_{\mathrm{w}}$ : weight-average molecular weight. ${ }^{b}$ Sulfonation degree is the molar ratio (\%) of Na-sDCDPS to total dihalides. ${ }^{c}$ DABPA content is the molar ratio (\%) of DABPA to total diols. The feed ratio means the loaded amount of reactants before synthesis. 
protonic-form (acid-form) membranes and then washed with deionized water until excess sulfuric acid had been completely removed..$^{45}$

\subsection{Characterization}

Nuclear magnetic resonance (NMR) experiments were performed on a Bruker Advance DPX 300 spectrometer equipped with a Bruker multinuclear z-gradient with a magnetic strength of $53.5 \mathrm{G} \mathrm{cm}^{-1}$ in the $z$ direction. The samples $(1.5 \mathrm{~g})$ were dissolved in deuterated dimethyl sulfoxide $(1 \mathrm{~mL})$ for ${ }^{1} \mathrm{H}$-NMR characterization. Molecular weights and polydispersity index (PDI) were measured using a Polymer Lab apparatus PLGPC210, equipped with two Tosoh Biosep G2500 PWXL PL gel mixed B columns and a Viscotek TDA302 refractive index detector at $40{ }^{\circ} \mathrm{C}$. Thermogravimetric analyses (TGA) were performed using a Perkin-Elmer TGA-7 instrument from room temperature to $700{ }^{\circ} \mathrm{C}$ with a ramping rate of $10{ }^{\circ} \mathrm{C}$ per min under a nitrogen atmosphere. For characterization of the dispersed morphology of LAPONITE®, membranes were molded with epoxy resin, sliced to yield a roughly $90 \mathrm{~nm}$ thick film using a RMC microtome Powertome XL, and placed on copper grids. Transmission electron microscopy (TEM) images were obtained using a Philips CM-20 scanning transmission electron microscope with an accelerating voltage of $200 \mathrm{kV}$. Mechanical properties of the membranes were measured using nano-indentation, XP of MTS. $\mathrm{X}$-ray diffraction (XRD) patterns were obtained by using a Philips X'pert Pro X-ray diffractometer, equipped with a $\mathrm{Cu} \mathrm{K} \alpha$ source $(\lambda=0.15406 \mathrm{~nm})$ at $30 \mathrm{kV}$ and $30 \mathrm{~mA}$. The diffractograms were scanned with a scanning rate of $2^{\circ} \mathrm{min}^{-1}$ in a $2 \theta$ range of $1.2-10^{\circ}$ at room temperature. Swelling behavior measurements of membranes in $\mathrm{MeOH}$ aqueous solution were carried out as follows. The membranes were dried under high vacuum at $110{ }^{\circ} \mathrm{C}$ for $12 \mathrm{~h}$. After being dried, the length, width and thickness of the membranes were measured and then immersed in a $\mathrm{MeOH}$ aqueous solution of $\mathrm{MeOH}$ (1 mol, $32 \mathrm{~g}$ ) and water ( $1 \mathrm{~mol}, 18 \mathrm{~g}$ ) for $24 \mathrm{~h}$ at room temperature. The sizes (length, width, and thickness) of the swollen membranes were re measured after removing the $\mathrm{MeOH}$ aqueous solution from membrane surfaces. Swelling ratio of each membrane (\%) was calculated using the size variation of the membrane in wet and dried states. Ion conductivity was evaluated by a four-point probe method using a Solartron 1260 a.c. impedance analyzer with an amplitude of $20 \mathrm{mV}$ and a frequency range of $1 \mathrm{~Hz}$ to $500 \mathrm{kHz}$. Each membrane $\left(1.5 \times 4.0 \mathrm{~cm}^{2}\right)$ was fitted in a Teflon conductivity test cell that consisted of two Pt wires (a counter electrode and a working electrode) and two Pt foils (reference electrode 1 and reference electrode 2). The Teflon test cell was immersed in a de-ionized water bath to maintain the membrane at constant humidity and temperature. Membrane resistance was calculated using the intercept value of the real axis $\left(Z^{\prime}\right)$ in the complex plane that is composed of the real axis and the imaginary axis $\left(Z^{\prime \prime}\right)$. Unit conductance $(k)$ was initially calculated via the following eqn (1):

$$
k=\left(\frac{1}{R}\right)\left(\frac{1}{A}\right)
$$

where $R$ is the resistance and $A$ is the cross-sectional area of a membrane.

Since unit conductance $(k)$ is extrinsically dependent on thickness, their intrinsic ionic conductivity $(\sigma)$ was calculated via the following eqn (2):

$$
\sigma=k \times L
$$

where $L$ is the thickness of a membrane.

$\mathrm{MeOH}$ permeability measurements were performed with a refractive index detector (RI750F, Young In Co., Korea). In detailed configuration, $\mathrm{MeOH}$ permeability measurements of the membranes were performed using a diffusion cell consisting of two reservoirs at room temperature. Membranes with a transporting area of $4 \mathrm{~cm}^{2}$ were placed between a $\mathrm{MeOH}$ reservoir and a water reservoir. The internal volume of each reservoir was $35 \mathrm{~mL}$. MeOH permeability was calculated using the following eqn (3), which describes the relationship between the $\mathrm{MeOH}$ concentration and elapsed time:

$$
P=\left(\frac{\Delta C_{\mathrm{B}}}{\Delta t}\right)\left(\frac{1}{C_{\mathrm{Ai}}}\right)\left(\frac{L}{A}\right) V_{\mathrm{B}}
$$

where $P$ is the permeability of a membrane; $\Delta C_{\mathrm{B}} / \Delta t$ is the slope of a molar concentration variation of methanol in the water reservoir as a function of time; $C_{\mathrm{Ai}}$ is the initial concentration of methanol in its reservoir; $L$ and $A$ are the thickness and the area of a membrane, respectively; $V_{\mathrm{B}}$ is the volume of de-ionized water in its reservoir. ${ }^{22,23}$

\subsection{Fabrication of membrane-electrode-assembly (MEA) and cell performance test}

For the fabrication of a MEA, cathode catalyst ink was prepared by dispersing a commercial Pt black catalyst (HiSpec 1000 from Johnson Matthey Fuel Cells) in alcohol solution with Nafion dispersion. The catalyst ink was coated onto a gas diffusion layer to form a cathode catalyst layer of $4.5 \mathrm{mg} \mathrm{cm} \mathrm{cm}^{-2} \mathrm{Pt}$. (HiSpec 6000 from Johnson Matthey Fuel Cells, Pt/Ru ratio = 1/1). Both electrodes and membranes were hot-pressed to fabricate a MEA with a reaction area of $10 \mathrm{~cm}^{2}$. Active DMFC single cell tests were conducted at $60{ }^{\circ} \mathrm{C}$ with $1 \mathrm{M} \mathrm{MeOH}$ aqueous solution and air as fuel for the anode and the cathode, respectively. The $\mathrm{MeOH}$ solution was fed into the anode by means of a microflow pump in an amount of a 2.5 stoichiometry. The performance of a single cell with a UV-crosslinked sPAS membrane was compared with that of a reference single cell with Nafion 115.

\section{Results and discussion}

\subsection{Synthesis and chemical analysis of UV-crosslinked sPAS}

As shown in Fig. 2, UV-crosslinkable sPAS random copolymers were synthesized from a mixture of two kinds of diol monomers (BPA and DABPA) and two kinds of dihalide monomers (DCDPS and Na-sDCDPS) by a condensation polymerization. The degree of crosslinking and the degree of sulfonation were controlled by adjusting the feed ratios of the UV-crosslinkable DABPA diol monomer (with allyl groups) and the sulfonated dihalide monomer of Na-sDCDPS, respectively, in the same 

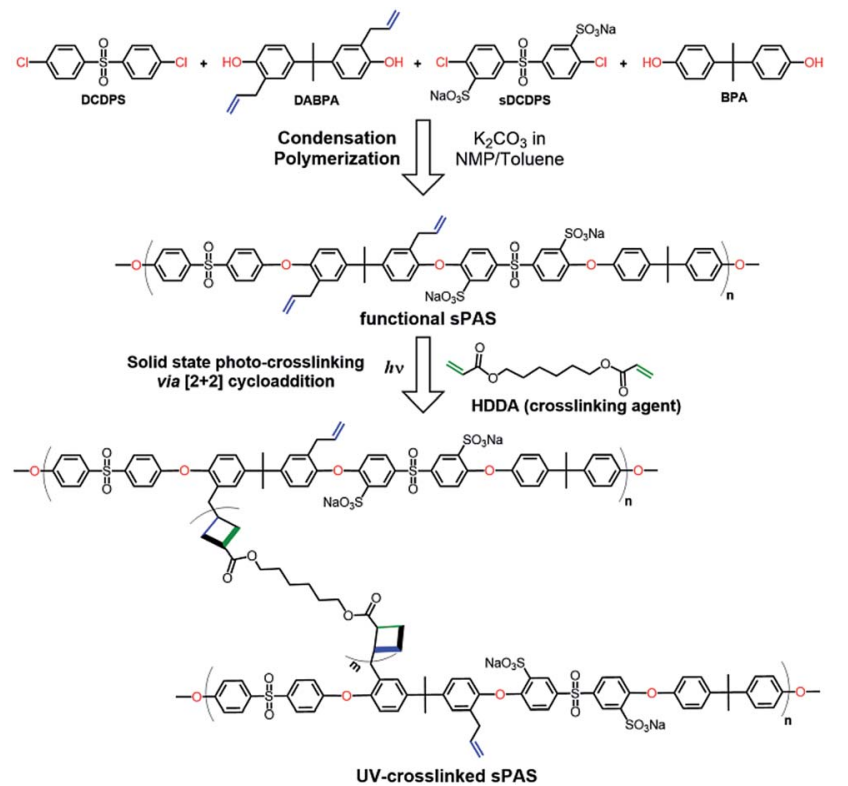

Fig. 2 Condensation random copolymerization for the synthesis of UV-crosslinkable sPAS and photo-crosslinking.

stoichiometric ratio of diols and dihalides. After polymerization, LAPONITE® nanofillers were homogeneously dispersed in the UV-crosslinkable sPAS matrix via simple solution intercalation without any dispersants or organic modifiers. Solid state $[2+2]$ photo-cycloadditions yielding a cyclobutane ring are known to be very useful for crosslinking in the field of polymer chemistry. ${ }^{46,47}$

In this regard, the photo-crosslinking of functional sPASs were achieved by the $[2+2]$ cycloaddition of crosslinking agent (HDDA) with allyl moieties bound to the sPAS backbone, which produced UV-crosslinked SPAS-LAPONITE® nanocomposite membranes. The chemical structure of as-prepared sPAS was confirmed with ${ }^{1} \mathrm{H}$ NMR spectrum (see Fig. 3 ). The NMR spectrum exhibits typical proton peaks, assigned as follows: a peak at $8.26 \delta$ for the proton neighboring sulfonic group of $\mathrm{Na}-$ SDCDPS $\left(\mathrm{c}^{\prime}\right)$; a peak at $7.88 \delta$ for the proton of DCDPS (a);

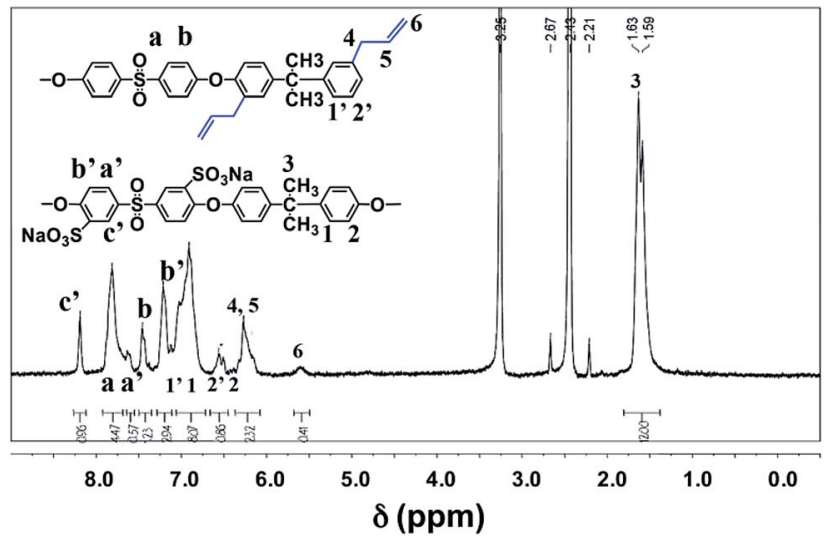

Fig. $3{ }^{1} \mathrm{H}$ NMR spectrum of sPAS synthesized with $30 \%$ of $\mathrm{Na}-$ sDCDPS in dihalides and $25 \%$ of DABPA in diols. a shoulder peak at $7.58 \delta$ for the proton positioned at the opposite side of the sulfonic moiety of Na-sDCDPS $\left(\mathrm{a}^{\prime}\right)$; a peak at $7.52 \delta$ for the protons of DCDPS (b); a peak at $7.27 \delta$ for the protons of Na-sDCDPS $\left(b^{\prime}\right)$; a peak at $7.02 \delta$ for $1,1^{\prime}$ (BPA and DABPA); $2,2^{\prime}$ peaks at $6.67 \delta$ for the protons of BPA and DABPA; $6.32 \delta$ for the allyl protons of DABPA $(4,5)$; a peak at $5.62 \delta$ for the ethylene proton of DABPA (6); a peak at $1.64 \delta$ for the methyl of the BPA (3). The NMR spectrum reveals that the vinyl bond in the allyl group was shifted to the next methylene bond to create a methyl group at the end of the allyl group after condensation polymerization. The contents of sulfonated (Na-sDCDPS) units and crosslinkable (DABPA) units incorporated into the polymer backbone were measured by integrating characteristic NMR peak areas. For the calculation of sulfonation degree, the areal ratio of the peak at $8.26 \delta$ (Na-sDCDPS) to the peak at $7.88 \delta$ (DCDPS) normalized with the number of corresponding hydrogen atoms for each dihalide were compared. The DABPA contents were estimated from the areal ratio of the peak at 7.02 $\delta$ (BPA) to that at $6.32 \delta$ (DABPA). The content of DABPA units incorporated in the sPAS backbone was substantially less than that of its feed composition. The steric hindrance of allyl side groups in DABPA is supposed to hinder the incorporation of DABPA into the polymer backbone (see Table 1). Nonetheless, all the synthesized sPAS showed high molecular weights, ranging from $800000 \mathrm{~g} \mathrm{~mol}^{-1}$ to $1240000 \mathrm{~g} \mathrm{~mol}^{-1}$, demonstrating that the incorporation of both DABPA and Na-sDCDPS monomers did not significantly influence the overall polymerization rate (ESI, Fig. S1 $\dagger$ ). It should be noted that the allyl group in the DABPA unit was not thermally crosslinked during polymerization when it was less than $50 \%$.

However, when its content was more than $50 \%$, reaction media underwent gelation.

\subsection{Glass transition temperature and dimensional stability}

Fig. 4 presents the variation of the glass transition temperature $\left(T_{\mathrm{g}}\right)$ of sPASs with the contents of crosslinkable DABPA unit and soft bridge HDDA additive. As shown in Fig. 4(a), the $T_{\mathrm{g}}$ of uncrosslinked sPAS decreased from $203{ }^{\circ} \mathrm{C}(0 \%$ of DABPA $)$ to $86.6^{\circ} \mathrm{C}(100 \%$ of DABPA $)$ with DABPA content. The decrease of a

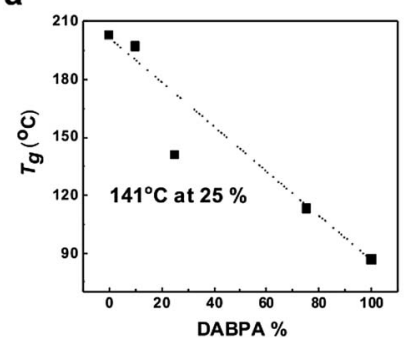

b

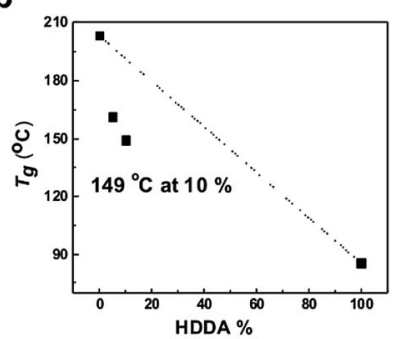

Fig. 4 The variation of $T_{\mathrm{g}}$ for (a) UV-crosslinkable sPASs (Na-sDCDPS content in dihalides: $30 \mathrm{~mol} \%$ ) with the content of UV-crosslinkable monomer, DABPA, and for (b) UV-crosslinked sPASs (Na-sDCDPS content in dihalides: 30 mol\%, DABPA content in diols: 25 mol\%) with the content of soft bridge molecule, HDDA. The HDDA content means the molar ratio of acrylate groups of HDDA to allyl groups in UVcrosslinked sPAS. 
$T_{\mathrm{g}}$ was attributed to the flexible allyl moiety in the DABPA unit. Fig. 4(b) shows the effect of a soft segment HDDA on the $T_{\mathrm{g}}$ of UV-crosslinked sPASs. Since polymerized HDDA has a low $T_{\mathrm{g}}$ of $\sim 62{ }^{\circ} \mathrm{C}$, the $T_{\mathrm{g}}$ of UV-cured sPASs with HDDA decreased with HDDA content from $203{ }^{\circ} \mathrm{C}$ to $85{ }^{\circ} \mathrm{C}$. These results signify that the $T_{\mathrm{g}}$ of our sPAS polymers can be tuned by the crosslinking density, which is governed by the feed ratio of DABPA and the amount of soft segment determined by the amount of HDDA, without sacrificing molecular weight. The dimensional stability of the UV-crosslinked sPAS membrane was tested by immersing it into NMP, a good solvent of uncrosslinked sPAS.

Two $5 \times 5 \mathrm{~mm}^{2}$ size crosslinked membranes were prepared and one was immersed in NMP for 48 h (Fig. 5). Fig. 5(b) shows that, unlike un-crosslinked polymers, which are highly swollen in NMP, the crosslinked membrane maintained its structural integrity. The dimensional stability of our UV-crosslinked sPAS was also tested in a harsh environment of a $3 \mathrm{M} \mathrm{MeOH}$ aqueous solution for $48 \mathrm{~h}$. The crosslinking greatly improved the dimensional stability (as revealed by a low degree of swelling) of the membrane (see Table $\mathrm{S} 1 \dagger$ ). The result indicates that the crosslinked polymers have better dimensional stability than uncrosslinked linear polymers.

\subsection{Effect of the UV-crosslinking and the incorporation of LAPONITE®}

To further improve the dimensional stability and barrier properties of the UV-crosslinkable sPAS membrane, nanosized LAPONITE® fillers were dispersed before crosslinking. The TEM image of a highly loaded (10 wt $\%$ ) nanocomposite reveals a homogeneously exfoliated morphology of LAPONITE® fillers in the sPAS matrix (Fig. 6(a)). The fully exfoliated and homogeneously dispersed morphology was well-preserved during UVcrosslinking.

The homogeneous dispersion of LAPONITE® in membrane can be attributed to their excellent compatibility with sPAS, which is directly related to polarity of sPAS. It is worthwhile to note that an increase concentration of sulfonic acid improves the compatibility between hygroscopic LAPONITE® and PAS matrix. ${ }^{48}$ As shown in Fig. 6(b), XRD measurements verified that the LAPONITE ${ }^{\circ}$ nanocomposites showed the exfoliated morphology up to $\sim 10 \mathrm{wt} \%$ LAPONITE® content, beyond which they showed intercalated morphology. The addition of a small amount of LAPONITE $®$ nanofillers has shown significant effects

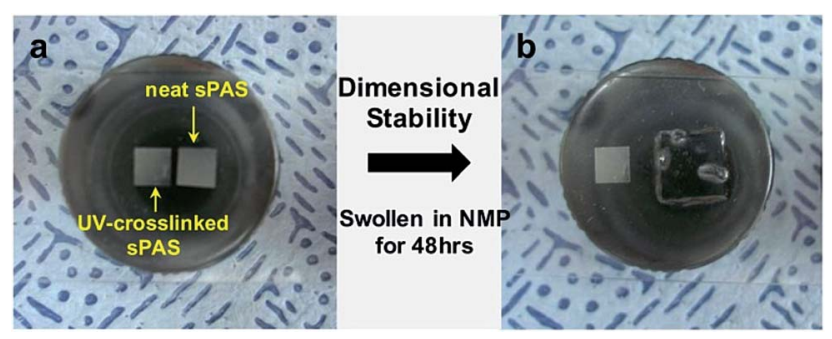

Fig. 5 Dimensional stability test of UV-crosslinked sPAS. (a) Two $5 \times 5$ $\mathrm{mm}^{2}$ size UV-crosslinked membranes were prepared. (b) The rightside membrane was swollen in NMP for $48 \mathrm{~h}$.
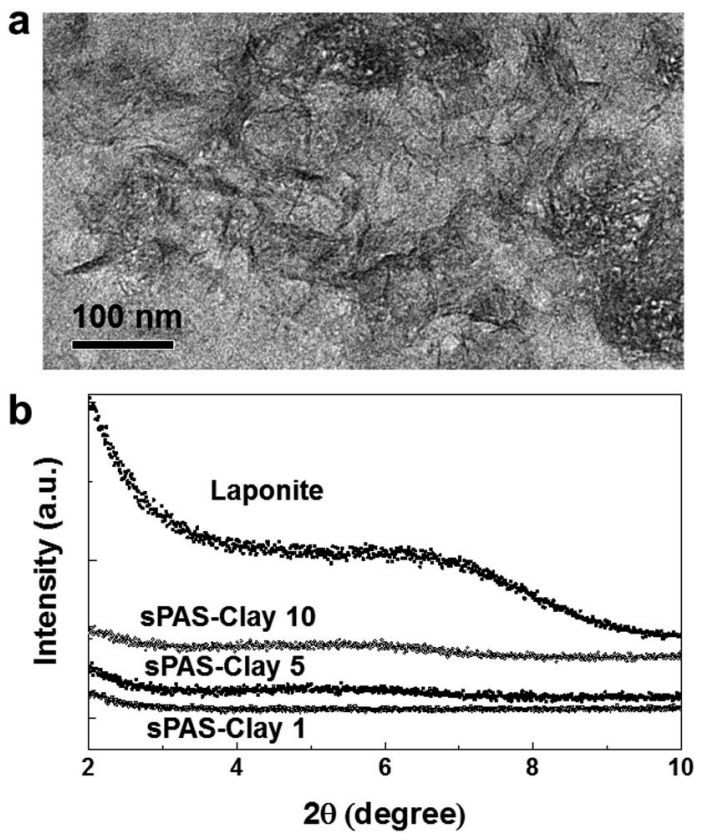

Fig. 6 (a) TEM image of sPAS nanocomposites with 10 wt\% of exfoliated clay fillers in SPAS matrix (Na-sDCDPS content in dihalides: 30 mol\%, DABPA content in diols: $25 \mathrm{~mol} \%$ ) and (b) XRD pattern of sPASclay nanocomposites prepared by adding LAPONITE $®$ dispersion into polymerization reactor after polymerization.

for the mechanical properties (Fig. 7). The elastic modulus and hardness for UV-crosslinked sPAS membrane were 6.2 GPa and $300 \mathrm{MPa}$, respectively. In the presence of $1 \mathrm{wt} \%$ of LAPONITE®, the elastic modulus and hardness were increased by $15 \%$ (7.1 $\mathrm{GPa}$ ) and 5\% (315 $\mathrm{MPa})$, respectively. It reveals that the UVcrosslinking and introduction of LAPONITE® offers better dimensional stability and stiffness over Nafion 115, as reflected in mechanical properties. As mentioned above, the dimensional stability of a PEM is closely related to its $\mathrm{MeOH}$ permeability and proton conductance. ${ }^{\mathbf{1 8 , 4 9}}$ These properties of UV-crosslinked PEMs without LAPONITE® nanofillers are summarized in Table 2. Without LAPONITE® filler, the major parameter affecting the permeability and proton conductance of PEM was the degree of sulfonation. As the degree of sulfonation increased, the $\mathrm{MeOH}$ permeability was deteriorated, while proton conductance was improved.
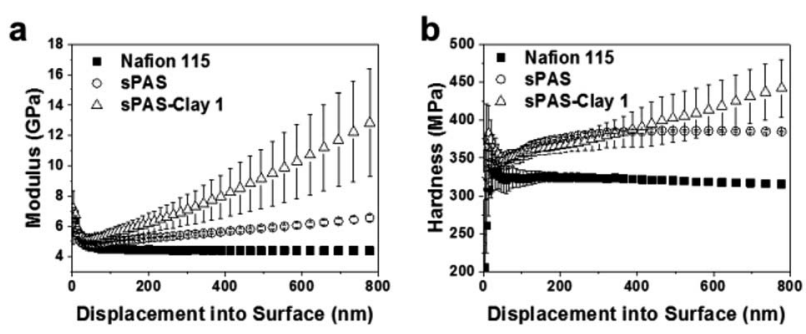

Fig. 7 (a) Young's modulus and (b) hardness of Nafion 115, UVcrosslinked SPAS, and UV-crosslinked SPAS-LAPONITE ${ }^{\circledR}$ composite membranes. The maximum indentation depth was set to be $1 \mu \mathrm{m}$. 
Table $2 \mathrm{MeOH}$ permeability and proton conductance of UV-crosslinked sPAS membranes

\begin{tabular}{lllll}
\hline & $\begin{array}{l}\text { Weight fraction of } \\
\text { Sample }^{a}\end{array}$ & $\begin{array}{l}\text { Ion conductivity } \\
{\left[\mathrm{S} \mathrm{cm}^{-1}\right]}\end{array}$ & $\begin{array}{l}\text { Permeability } \\
{\left[\times 10^{-7} \mathrm{~cm}^{2} \mathrm{~s}^{-1}\right]}\end{array}$ & $\begin{array}{l}\text { Selectivity } \\
{\left[\times 10^{5} \mathrm{~S} \mathrm{~s} \mathrm{~cm}^{-3}\right]}\end{array}$ \\
\hline SPAS & 0 & 0.038 & 4.85 & 0.78 \\
{$\left[\mathrm{~S} \mathrm{~cm}^{-2}\right]$}
\end{tabular}

${ }^{a} \mathrm{Na}$-sDCDPS/DABPA/HDDA mean the molar ratio (\%) of specific reactants to total dihalides/diols/diallyl groups of loaded reactants. ${ }^{b}$ Selectivity $=$ ion conductivity/MeOH permeability.

To better understand the combined effect of ion conductivity, thickness, and methanol permeability, we have calculated the membrane selectivity, as the proton conductivity divided by the $\mathrm{MeOH}$ permeability. From the selectivity, it shows clearly that a low degree of sulfonation improves the selectivity. Nevertheless, it should be noted that a low degree of sulfonation definitely lowers the entire unit conductance, as it has lower ionic exchange capacity (IECs). Interestingly, the content of soft linker HDDA did not influence the $\mathrm{MeOH}$ permeability or proton conductance of the crosslinked membranes. This demonstrates that the incorporation of HDDA with UVcrosslinking improved the dimensional stability of the SPAS membrane without sacrificing proton conductance.

Table 3 shows the permeability and proton conductance of SPAS-LAPONITE ${ }^{\circledR}$ nanocomposites as a function of LAPONITE® fillers. It should be noted that all sPAS composite membranes have been fabricated with sPAS having $30 \%$ of NasDCDPS in dihalides, $25 \%$ of DABPA in diols, and 10\% HDDA. The data shown in Table 3 also confirms that UV-crosslinking did not degrade the proton conductance of the membranes, while the incorporation of LAPONITE® nanofillers greatly improved their barrier properties. Remarkably, the LAPONITE $®$ nanocomposite membranes exhibited permeability values of 2.7-2.9 $\times 10^{-7} \mathrm{~cm}^{2} \mathrm{~s}^{-1}$, which are significantly reduced from the value of a neat SPAS membrane without LAPONITE® filler. Despite the dramatic reduction of $\mathrm{MeOH}$ permeability, the proton conductivity maintained almost the same value even at a high content of LAPONITE® fillers of up to $10 \mathrm{wt} \%$. Consequently, homogeneously exfoliated LAPONITE® encouraged the remarkable selectivity $\left(1.2-1.3 \times 10^{5} \mathrm{~S} \mathrm{~s} \mathrm{~cm}^{-3}\right)$, compared to the LAPONITE®-free control sample $\left(0.78 \times 10^{5} \mathrm{~S} \mathrm{~s} \mathrm{~cm}^{-3}\right)$ and Nafion $115\left(0.67 \times 10^{5} \mathrm{~S} \mathrm{~s} \mathrm{~cm}^{-3}\right)$.

This is mainly due to a significant reduction in $\mathrm{MeOH}$ crossover, which is directly related to the presence of impermeable LAPONITE® platelets as well as microstructure change induced by LAPONITE ${ }^{.50,51}$ Additionally, the microstructure (Fig. 6(a)) of sPAS-LAPONITE® $(1 \mathrm{wt} \%)$ composite membranes confirms the alterations of the network structure, which directly influences mass transport of water and methanol.

\subsection{DMFC performance}

To investigate electrochemical behavior, the performance of UV-crosslinked nanocomposite membranes in a DMFC cell was tested in a single cell with an active area of $10 \mathrm{~cm}^{2}$. Fig. 8 shows the polarization curves of DMFCs obtained from a voltage scan. The single cell incorporated with UV-crosslinked sPASLAPONITE® nanocomposite membrane (1 wt\%) exhibited better performance than UV-crosslinked sPAS membrane without nanofillers and the Nafion 115-based cell: the maximum power-density value at $60{ }^{\circ} \mathrm{C}$ of the former was 117.1 $\mathrm{mW} \mathrm{cm}^{-2}$, which is significantly higher than those (96.5 and $82.1 \mathrm{~mW} \mathrm{~cm}^{-2}$ ) for UV-crosslinked sPAS membrane and Nafion

Table $3 \mathrm{MeOH}$ permeability and proton conductance of UV-crosslinked sPAS-LAPONITE® nanocomposite membranes

\begin{tabular}{|c|c|c|c|c|c|}
\hline $\begin{array}{l}\text { Na-sDCDPS/DABPA/ } \\
\text { HDDA }^{a}\end{array}$ & $\begin{array}{l}\text { Thickness } \\
\text { [wet, } \mu \mathrm{m}]\end{array}$ & $\begin{array}{l}\text { Ion conductivity } \\
{\left[\mathrm{S} \mathrm{cm}^{-1}\right]}\end{array}$ & $\begin{array}{l}\text { Permeability } \\
{\left[\times 10^{-7} \mathrm{~cm}^{2} \mathrm{~s}^{-1}\right]}\end{array}$ & $\begin{array}{l}\text { Selectivity }^{b} \\
{\left[\times 10^{5} \mathrm{~S} \mathrm{~s} \mathrm{~cm}^{-3}\right]}\end{array}$ & $\begin{array}{l}\text { Ion conductance } \\
{\left[\mathrm{S} \mathrm{cm}^{-2}\right]}\end{array}$ \\
\hline $30 / 25 / 0$ & 45 & 0.039 & 4.85 & 0.81 & 8.7 \\
\hline $30 / 25 / 10$ & 45 & 0.038 & 4.85 & 0.78 & 8.4 \\
\hline $25 / 25 / 0$ & 45 & 0.030 & 2.95 & 1.02 & 6.7 \\
\hline $20 / 25 / 0$ & 45 & 0.021 & 0.39 & 5.31 & 4.7 \\
\hline $20 / 25 / 50$ & 45 & 0.025 & 0.54 & 4.66 & 5.6 \\
\hline Nafion 115 & 140 & 0.094 & 13.8 & 0.68 & 6.7 \\
\hline
\end{tabular}

${ }^{a}$ All sPAS composite membranes have constant the specific molar \% ratio (30/25/10) of Na-sDCDPS/DABPA/HDDA. ${ }^{b}$ Weight fraction of LAPONITE $®$ is the weight ratio of LAPONITE $®$ to polymer matrix. ${ }^{c}$ All sPAS composite membranes have constant thickness of $45 \mu \mathrm{m}$ (wet state) and Nafion 115 has thickness of $140 \mu \mathrm{m}$ (wet state). 


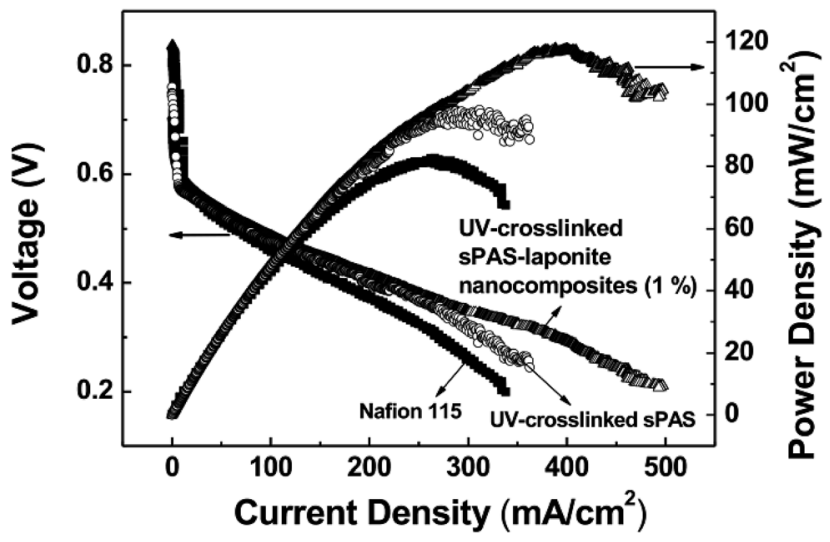

Fig. 8 Polarization and power density curves of DMFC single cells equipped with UV-crosslinked SPAS-LAPONITE ${ }^{\circledR}$ nanocomposite membrane, UV-crosslinked sPAS membrane without clay and Nafion 115. The UV-crosslinked sPASs were prepared with 25 mol\% of HDDA in total allyl groups ( $\mathrm{Na}-\mathrm{sDCDPS}$ content in dihalides: $30 \mathrm{~mol} \%$, DABPA content in diols: 25 mol\%). The LAPONITE® content was 1 wt\%.

115, respectively. The better performance with sPASLAPONITE® composite membranes could be attributed to two effects. Considering low $\mathrm{MeOH}$ crossover, less methanol permeating through the membranes ultimately lead to an increase in open circuit voltage $(0.84 \mathrm{~V})$ with less oxidizing of $\mathrm{MeOH}$ in cathode catalytic layers. Additionally, the high ionic conductance of SPAS-LAPONITE® composite membranes could lower ohmic resistance values, which was confirmed in our previous work. ${ }^{23}$

\section{Conclusion}

We have demonstrated UV-crosslinked SPAS-LAPONITE ${ }^{\circledR}$ nanocomposite PEMs showing remarkable performance. UVcrosslinking of the polymer backbone via $[2+2]$ cycloaddition and homogeneous exfoliation of LAPONITE® nanofillers enhanced the dimensional stability and $\mathrm{MeOH}$ barrier property of the sPAS membrane, while maintaining high proton conductivity. A single cell DMFC, incorporating a crosslinked nanocomposite membrane, exhibited remarkable performance (maximum power-density of $117.1 \mathrm{~mW} \mathrm{~cm}^{-2}$ ), which exceeds that of a commercially available Nafion 115-based cell (maximum power-density of $82.1 \mathrm{~mW} \mathrm{~cm}^{-2}$ ) under the same operating conditions. Our strategy of crosslinked nanocomposite preparation is potentially useful for the fabrication of robust film, solid-electrolyte, and functional membranes based on various polymers.

\section{Acknowledgements}

This work was supported by Samsung Advanced Institute of Technology.

\section{Notes and references}

1 B. C. H. Steele and A. Heinzel, Nature, 2001, 414, 345-352.
2 J. R. Varcoe and R. C. T. Slade, Fuel Cells, 2005, 5, 187-200.

3 Y. Wang, K. S. Chen, J. Mishler, S. C. Cho and X. C. Adroher, Appl. Energy, 2011, 88, 981-1007.

4 H. Zhang and P. K. Shen, Chem. Rev., 2012, 112, 2780-2832.

5 K. D. Kreuer, J. Membr. Sci., 2001, 185, 29-39.

6 R. Dillon, S. Srinivasan, A. S. Aricò and V. Antonucci, J. Power Sources, 2004, 127, 112-126.

7 T. E. Springer, T. A. Zawodzinski and S. Gottesfeld, J. Electrochem. Soc., 1991, 138, 2334-2342.

8 V. Neburchilov, J. Martin, H. Wang and J. Zhang, J. Power Sources, 2007, 169, 221-238.

9 M. A. Hickner, A. M. Herring and E. B. Coughlin, J. Polym. Sci., Part B: Polym. Phys., 2013, 51, 1727-1735.

10 C. H. Lee, H. B. Park, Y. S. Chung, Y. M. Lee and B. D. Freeman, Macromolecules, 2006, 39, 755-764.

11 A. Aricò, D. Sebastian, M. Schuster, B. Bauer, C. D'Urso, F. Lufrano and V. Baglio, Membranes, 2015, 5, 793.

12 K. A. Mauritz and R. B. Moore, Chem. Rev., 2004, 104, 45354586.

13 R. Souzy and B. Ameduri, Prog. Polym. Sci., 2005, 30, 644687.

14 A. Heinzel and V. M. Barragán, J. Power Sources, 1999, 84, 7074.

15 S. J. Peighambardoust, S. Rowshanzamir and M. Amjadi, Int. J. Hydrogen Energy, 2010, 35, 9349-9384.

16 F. Lufrano, V. Baglio, P. Staiti, V. Antonucci and A. S. Arico, J. Power Sources, 2013, 243, 519-534.

17 A. Kraytsberg and Y. Ein-Eli, Energy Fuels, 2014, 28, 73037330 .

18 E. Bakangura, L. Wu, L. Ge, Z. Yang and T. Xu, Prog. Polym. Sci., 2016, 57, 103-152.

19 K. H. Lee, D. H. Cho, Y. M. Kim, S. J. Moon, J. G. Seong, D. W. Shin, J.-Y. Sohn, J. F. Kim and Y. M. Lee, Energy Environ. Sci., 2017, 10, 275-285.

20 P. Wen, Z. Zhong, L. Li, F. Shen, X.-D. Li and M.-H. Lee, J. Membr. Sci., 2014, 463, 58-64.

21 B. Bae, T. Hoshi, K. Miyatake and M. Watanabe, Macromolecules, 2011, 44, 3884-3892.

22 T. K. Kim, M. Kang, Y. S. Choi, H. K. Kim, W. Lee, H. Chang and D. Seung, J. Power Sources, 2007, 165, 1-8.

23 Y. S. Choi, T. K. Kim, E. A. Kim, S. H. Joo, C. Pak, Y. H. Lee, H. Chang and D. Seung, Adv. Mater., 2008, 20, 2341-2344.

24 S. H. Joo, C. Pak, E. A. Kim, Y. H. Lee, H. Chang, D. Seung, Y. S. Choi, J.-B. Park and T. K. Kim, J. Power Sources, 2008, 180, 63-70.

25 T. Ko, K. Kim, B.-K. Jung, S.-H. Cha, S.-K. Kim and J.-C. Lee, Macromolecules, 2015, 48, 1104-1114.

26 B. G. Choi, J. Hong, Y. C. Park, D. H. Jung, W. H. Hong, P. T. Hammond and H. Park, ACS Nano, 2011, 5, 5167-5174.

27 D. Paradesi, D. Samanta, A. B. Mandal and S. N. Jaisankar, RSC Adv., 2014, 4, 26193-26200.

28 J. Pang, S. Feng, H. Zhang, Z. Jiang and G. Wang, RSC Adv., 2015, 5, 38298-38307.

$29 \mathrm{~J} . \mathrm{Xu}, \mathrm{Z}$. Wang, H. Zhang, H. Ni, X. Luo and B. Liu, RSC Adv., 2016, 6, 27725-27737.

30 C. H. Lee, K.-S. Lee, O. Lane, J. E. McGrath, Y. Chen, S. Wi, S. Y. Lee and Y. M. Lee, RSC Adv., 2012, 2, 1025-1032. 
31 Y. S. Kim, M. A. Hickner, L. Dong, B. S. Pivovar and J. E. McGrath, J. Membr. Sci., 2004, 243, 317-326.

32 L. Fu, G. Xiao and D. Yan, ACS Appl. Mater. Interfaces, 2010, 2, 1601-1607.

33 S. Takamuku and P. Jannasch, Polym. Chem., 2012, 3, 12021214.

34 D. W. Shin, S. Y. Lee, N. R. Kang, K. H. Lee, M. D. Guiver and Y. M. Lee, Macromolecules, 2013, 46, 3452-3460.

35 Y. H. Kwon, S. C. Kim and S.-Y. Lee, Macromolecules, 2009, 42, 5244-5250.

36 P. Wen, Z. Zhong, L. Li, A. Zhang, X.-D. Li and M.-H. Lee, J. Mater. Chem., 2012, 22, 22242-22249.

37 A. H. N. Rao, S. Nam and T.-H. Kim, Int. J. Hydrogen Energy, 2014, 39, 5919-5930.

38 Y. Z. Zhuo, A. Nan Lai, Q. G. Zhang, A. M. Zhu, M. L. Ye and Q. L. Liu, J. Membr. Sci., 2015, 491, 138-148.

39 M. M. Hasani-Sadrabadi, E. Dashtimoghadam, S. R. Ghaffarian, M. H. Hasani Sadrabadi, M. Heidari and H. Moaddel, Renewable Energy, 2010, 35, 226-231.

40 M. Ueda, H. Toyota, T. Ouchi, J.-I. Sugiyama, K. Yonetake, T. Masuko and T. Teramoto, J. Polym. Sci., Part A: Polym. Chem., 1993, 31, 853-858.
41 H. Zhang, H. Zhang, X. Li, Z. Mai, W. Wei and Y. Li, J. Power Sources, 2012, 217, 309-315.

42 C. Esposito Corcione, R. Striani and M. Frigione, Prog. Org. Coat., 2014, 77, 803-812.

43 K. Ma and Z. An, Macromol. Rapid Commun., 2016, 37, 15931597.

44 K.-S. Lee, M.-H. Jeong, J.-P. Lee and J.-S. Lee, Macromolecules, 2009, 42, 584-590.

45 C. H. Park, S. Y. Lee, D. S. Hwang, D. W. Shin, D. H. Cho, K. H. Lee, T.-W. Kim, T.-W. Kim, M. Lee, D.-S. Kim, C. M. Doherty, A. W. Thornton, A. J. Hill, M. D. Guiver and Y. M. Lee, Nature, 2016, 532, 480-483.

46 T. Junkers, Eur. Polym. J., 2015, 62, 273-280.

47 V. Ramamurthy and K. Venkatesan, Chem. Rev., 1987, 87, 433-481.

48 H. Zhang and P. K. Shen, Chem. Soc. Rev., 2012, 41, 23822394.

49 D.-J. Kim, H.-Y. Hwang, S.-b. Jung and S.-Y. Nam, J. Ind. Eng. Chem., 2012, 18, 556-562.

50 I. Nicotera, K. Angjeli, L. Coppola, A. S. Aricò and V. Baglio, Membranes, 2012, 2, 325.

51 Y. Lee, T. K. Kim and Y. S. Choi, Fuel Cells, 2013, 13, 173-180. 